E International

\title{
Urban Rail Development in Tokyo From 2000 to 2010
}

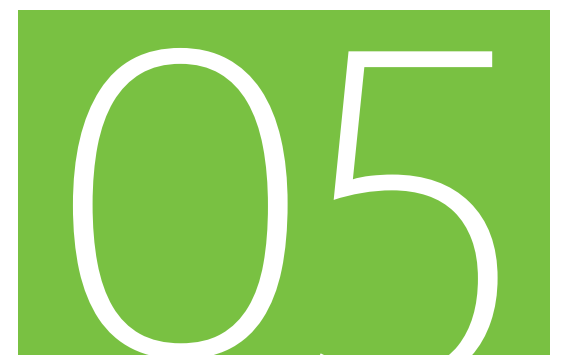

Discussion Paper 2014• 05

Hironori Kato

The University of Tokyo, Japan 


\section{Urban Rail Development in Tokyo From 2000 to 2010}

Discussion Paper No. 2014-05

Report for the ITF - KOTI Seminar

(March 27, 2014, Seoul)

Hironori Kato

The University of Tokyo, Japan

March 2014 
The International Transport Forum at the OECD is an intergovernmental organisation with 54 member countries. It acts as a strategic think-tank, with the objective of helping shape the transport policy agenda on a global level and ensuring that it contributes to economic growth, environmental protection, social inclusion and the preservation of human life and well-being. The International Transport Forum organises an annual summit of Ministers along with leading representatives from industry, civil society and academia.

The International Transport Forum was created under a Declaration issued by the Council of Ministers of the ECMT (European Conference of Ministers of Transport) at its Ministerial Session in May 2006 under the legal authority of the Protocol of the ECMT, signed in Brussels on 17 October 1953, and legal instruments of the OECD.

The Members of the Forum are: Albania, Armenia, Australia, Austria, Azerbaijan, Belarus, Belgium, Bosnia and Herzegovina, Bulgaria, Canada, Chile, People's Republic of China, Croatia, Czech Republic, Denmark, Estonia, Finland, France, Former Yugoslav Republic of Macedonia, Georgia, Germany, Greece, Hungary, Iceland, India, Ireland, Italy, Japan, Korea, Latvia, Liechtenstein, Lithuania, Luxembourg, Malta, Mexico, Republic of Moldova, Montenegro, the Netherlands, New Zealand, Norway, Poland, Portugal, Romania, Russian Federation, Serbia, Slovak Republic, Slovenia, Spain, Sweden, Switzerland, Turkey, Ukraine, United Kingdom and United States.

The International Transport Forum's Research Centre gathers statistics and conducts co-operative research programmes addressing all modes of transport. I ts findings are widely disseminated and support policymaking in Member countries as well as contributing to the annual summit.

\section{Discussion Papers}

The International Transport Forum's Discussion Paper Series makes economic research, commissioned or carried out at its Research Centre, available to researchers and practitioners. The aim is to contribute to the understanding of the transport sector and to provide inputs to transport policy design.

ITF Discussion Papers should not be reported as representing the official views of the ITF or of its member countries. The opinions expressed and arguments employed are those of the authors.

Discussion Papers describe preliminary results or research in progress by the author(s) and are published to stimulate discussion on a broad range of issues on which the ITF works. Comments on Discussion Papers are welcomed, and may be sent to: International Transport Forum/OECD, 2 rue André-Pascal, 75775 Paris Cedex 16, France.

For further information on the Discussion Papers and other JTRC activities, please email: itf.contact@oecd.org

The Discussion Papers can be downloaded from:

www. internationaltransportforum. org/jtrc/DiscussionPapers/jtrcpapers.html

The International Transport Forum's website is at: www. internationaltransportforum.org

This document and any map included herein are without prejudice to the status of or sovereignty over any territory, to the delimitation of international frontiers and boundaries and to the name of any territory, city or area. 
TABLE OF CONTENTS

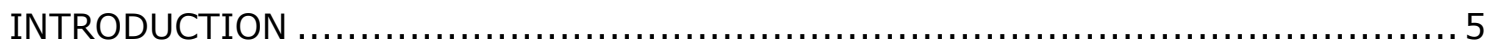

THE 2000 URBAN RAIL DEVELOPMENT MASTER PLAN IN TOKYO ................... 6

URBAN RAIL DEVELOPMENT AND ITS IMPACTS FOLLOWING

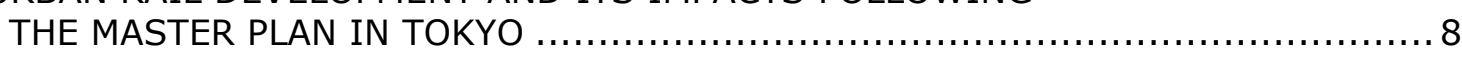

Urban Rail Development following the Latest Master Plan in Tokyo ................... 8

Policy-Target Achievements for the Latest Master Plan in Tokyo...................... 9

RECENT ISSUES REGARDING URBAN RAIL SERVICE IN TOKYO .................... 21

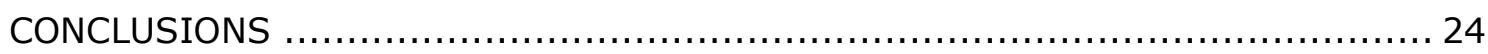

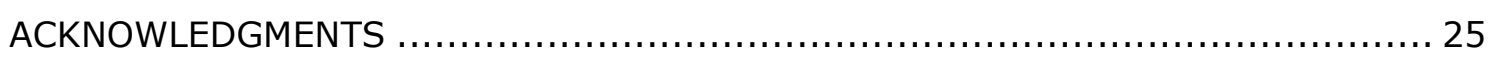

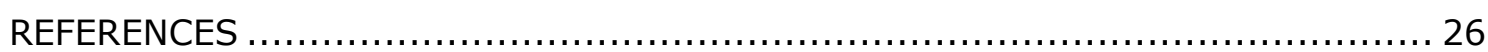





\section{INTRODUCTION}

Tokyo is well known as a rail-oriented city where the huge traffic demand generated from the megacity is well supported by a sophisticated urban rail system. The results of the 2008 Person Trip Survey show that rail's modal share was $30 \%$ as of 2008 ; the economy of Tokyo is highly dependent on an efficient urban rail network. As shown in Kato (2014), Tokyo's urban rail market has unique characteristics: private rail companies provide many of the rail services, the rail network was developed under the guidance of the central government, rail users suffered from chronic traffic congestion for many years, and the rail market has recently been significantly influenced by a rapidly aging demographic. In spite of its uniqueness, the experiences of urban rail development in Tokyo could be useful for other OECD member countries.

The urban rail network in the Tokyo Metropolitan Area was developed over the past 100 years under the "master plan" system (Morichi, 2000), which contains both the long-term rail network development projects and the service improvement programs proposed by the central government. The latest master plan was created in 2000 and presented in Report No. 18 of the Council for Transport Policy. The current master plan covers the period from 2000 to 2015; therefore, the next plan should be prepared by 2015 . The government has started to review the recent performance of urban rail service and have been discussing the next strategies of urban rail network development in the Tokyo Metropolitan Area. This paper aims to introduce the latest master plan, to review the recent development following the proposal of the latest master plan, and to discuss the current issues regarding Tokyo's rail network.

The paper is organized as follows: The next section will quickly explain the 2000 Urban Rail Development Master Plan in Tokyo. Recent urban development is reviewed, and the achievement of policy targets set in the master plan is examined. Then, the policy issues for the next master plan will be presented. Finally, some additional issues are summarized. It should be noted that this paper relies heavily on the report in MLIT (2012), which was prepared for the Research Committee on Current Problems and Future Direction of Railway Development in the Tokyo Metropolitan Area, organized by the Ministry of Land, Infrastructure, Transport, and Tourism (MLIT), Japan. 


\section{THE 2000 URBAN RAIL DEVELOPMENT MASTER PLAN IN TOKYO}

MLIT finalized the 2000 Urban Rail Development Master Plan in January 2000 (Morichi, 2000). This plan presents an ideal picture of the Tokyo Metropolitan Area's urban rail network in 2015, as well as the necessary rail developments. It identified five major policy targets for solving the expected problems in Tokyo's urban rail market: "Reduction of in-vehicle crowding," "Saving travel time," "Contribution to urban redevelopment," "Improvement of accessibility to airports and high-speed rail," and "Development of seamless transport network by introducing barrier-free facilities."

The first target is a policy issue related to congestion in Tokyo that has not yet been solved. The government stated that the congestion rate in 31 major rail sections should be equal to or lower than $150 \%$ during peak morning hours. Note that the government has regularly monitored in-vehicle traffic congestion in major rail lines in Tokyo.

The second target relates to the Tokyo Metropolitan Area's decentralized land-use policy, which has resulted in satellite sub-centers being developed for business. Strategies for saving travel time for rail connections between sub-centers were pursued, as were strategies for saving travel time when commuting from residential areas to business districts.

The third target aims to increase rail capacity, particularly in the central business district (CBD) of Tokyo. Since the 1990s, a number of high-rise buildings were built for both business and residential use in the CBD. This is due to the redevelopment of seaside areas near Tokyo Bay for business and residential use, and also because the younger generation has gradually changed its living-space preferences from suburban residential areas to the central area. These changes in land-use patterns are expected to generate a large volume of traffic.

The fourth target follows the globalization of business and tourism markets. The government has also implemented a globalization policy that includes the deregulation of the air transportation market and the promotion of tourism in Japan. The improvement of rail access both to and from airports, and of high-speed rail, is critical for better business and tourism conditions.

Finally, the fifth target reflects Japan's rapidly aging society. Social participation by seniors is widely understood to have a vitalizing effect on economic activities under the depopulation trend, and easy access to social services could be one of the drivers for providing them with better mobility in urban areas. Thus, the introduction of new devices and upgrades to station facilities for handicapped passengers was highly recommended.

The 2000 Urban Rail Development Master Plan also presented a list of rail development projects that were recommended for implementing construction or studying feasibility. The map in Figure 1 depicts the recommended network. The proposed projects are categorized into three types: A1 routes that are suitable for operation by the target year, 
$A 2$ routes that are suitable to begin development by the target year, and $B$ routes that must be developed or studied in the future. The rail projects in the A1 routes are considered the highest priority, which may mean that they are strongly supported by the government. In the A1 projects, stakeholders have reached, or have almost reached, a consensus; thus, these projects can be started immediately following the completion of the official process. Rail projects in the $A 2$ routes are considered medium priority, which means that they are supported by the government, but there may be some reasons why they cannot immediately be started, such as technical problems in construction or contract problems between different companies. B projects are typically considered important from the viewpoint of government targets, but they may not satisfy necessary conditions, such as cost-benefit criteria or financial viability criteria. Thus, further feasibility studies are required. The total length of all of the proposed projects is $658 \mathrm{~km}$. The length of the $A 1, A 2$, and $B$ routes are $288.0 \mathrm{~km}, 166.8 \mathrm{~km}$, and $203.3 \mathrm{~km}$, respectively.

Figure 1. Urban Railway Network Master Plan for the Tokyo Metropolitan Area from 2000 to 2011

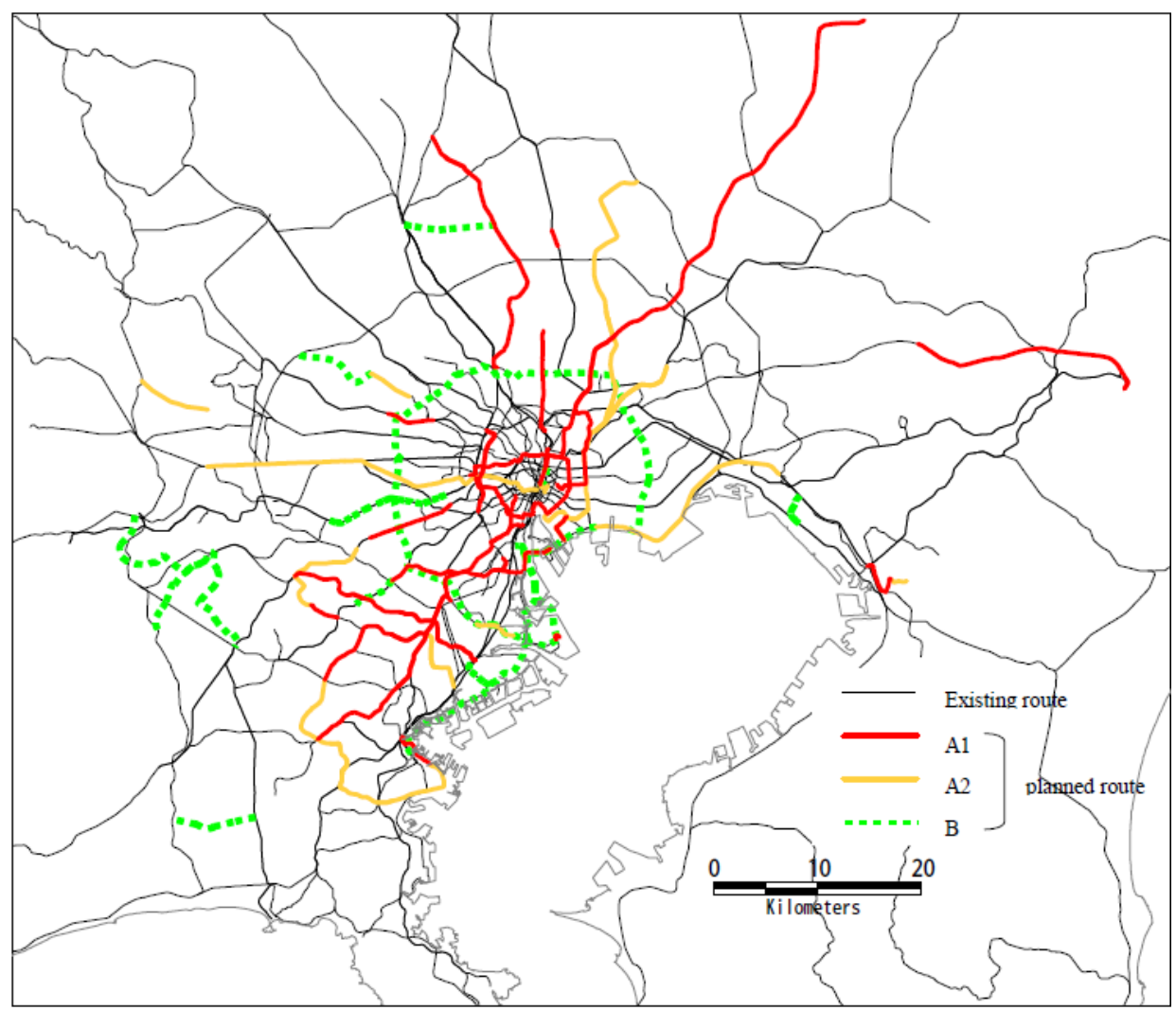

Source: Morichi et al. (2001)

In addition to the new construction projects, the 2000 Urban Rail Development Master Plan also proposed the improvement of existing rail lines. It includes the renovation of freight rail lines into passenger rail lines, the improvement of rail facilities for direct-through operations that connect one line with another, the increase in capacity of existing rail lines, the installation of facilities for switch-backs and additional tracks for overtaking, the upgrading of existing rail stations, the reformation of rolling stocks with additional trains, etc. 


\section{URBAN RAIL DEVELOPMENT AND ITS IMPACTS FOLLOWING THE MASTER PLAN IN TOKYO}

\section{Urban Rail Development following the Latest Master Plan in Tokyo}

Figure 2 presents the change over time for the length of the developed rail network in the Tokyo Metropolitan Area from 2000 to 2011 by the type of project. It shows that rail development has been implemented, gradually, almost every year. The developed length increased from 2005 to 2006 because the Tsukuba Express Line connecting Akihabara with Tsukuba began operating in 2005. It also shows the major improvement to existing lines, the introduction of the monorail, etc., which have all started since 2006. Figure 3 presents the major new urban rail lines that were completed or planned after 2008. Two of them-Tohoku-Jukan Line and direct-through Sotetsu and JR line-are still planned to be completed by 2015 and 2018, respectively. About $80 \%$ of the proposed A1 projects were completed by 2012 , while only $1 \%$ of the proposed $A 2$ projects were completed by 2012. No construction has begun yet on any B project.

Figure 2. Length of the rail network developed in the Tokyo Metropolitan Area from 2000 to 2011

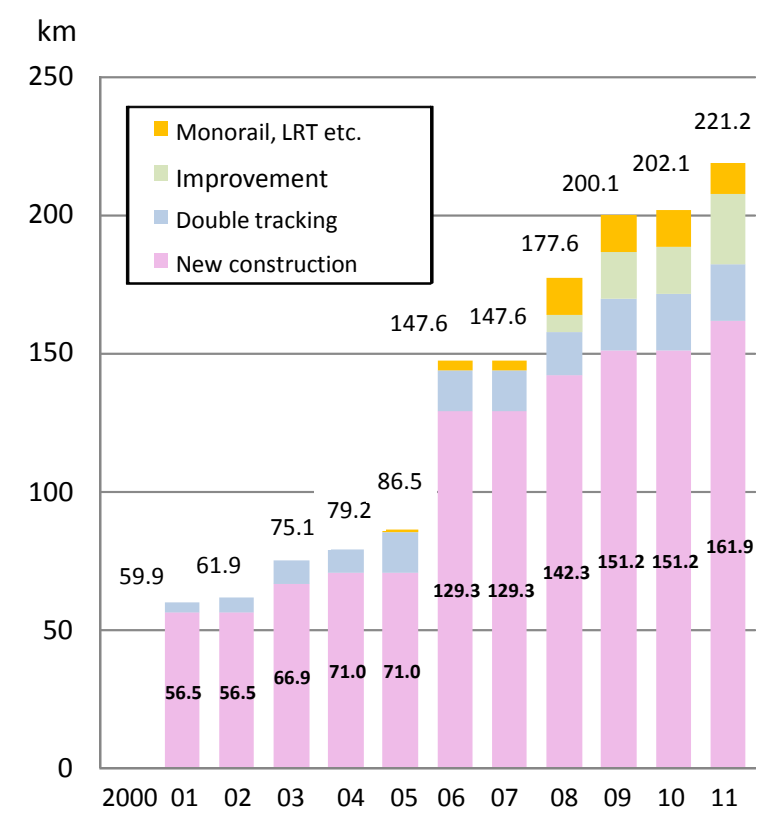

Source: MLIT (2012) 
Figure 3. Newly developed rail lines after 2008

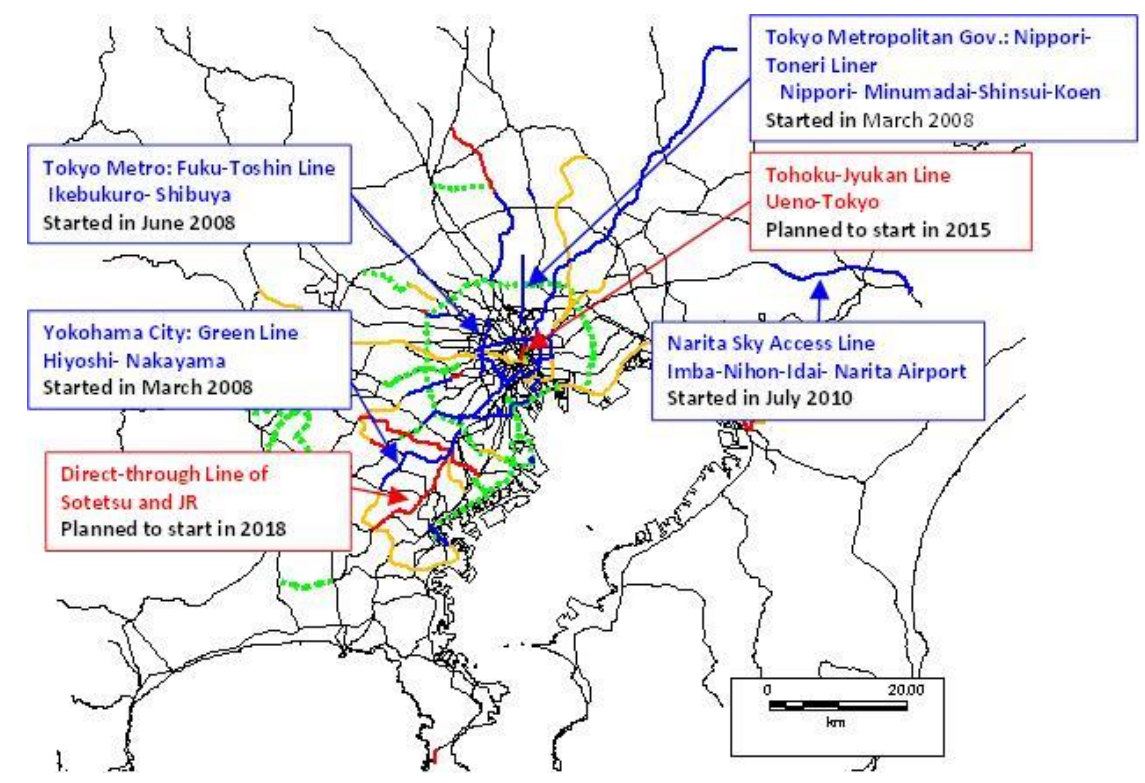

Source: MLIT (2012)

\section{Policy-Target Achievements for the Latest Master Plan in Tokyo}

\section{Reduction of in-vehicle crowding}

Figure 4 presents changes over time for in-vehicle congestion, with traffic volume and capacity, in 31 major sections of Tokyo from 1975 to 2010. A section's in-vehicle congestion rate is defined as the section's volume of traffic divided by the section's traffic capacity. Note that "section" refers to the link connecting one station with another station. A section's traffic volume represents the hourly traffic demand that passes through a given section, while the link's traffic capacity represents the hourly traffic capacity in that section. Traffic capacity is computed using the service frequency running through the section, the number of cars in a rolling stock, and the capacity of a car body as defined by the Japan Industrial Standard (JIS) (for more details, see Kato, 2014). Also note that Figure 4 standardizes the traffic volume and capacity according to 1975 values.

Figure 4 indicates that the average in-vehicle congestion rate decreased from $221 \%$ in 1975 to $171 \%$ in 2003, after which point it has remained almost stable. The decline in the in-vehicle congestion rate was mainly caused by an increase in traffic capacity. Although both traffic capacity and traffic volume increased between 1975 and 1993, the growth rate of traffic capacity is higher than that of traffic volume. This means that rail operators invested in projects that enhanced rail capacity, such as the construction of quadruple tracks, increases in service frequency, and the introduction of high-capacity car bodies. Additionally, in 1993 traffic volume began to decrease. The recent decline in traffic volume reflects a decrease in the population of workers, as well as changes in land-use patterns in the metropolitan area. The rapidly aging population and shrinking birth rate have led to a decrease in the number of workers in Tokyo. 
Figure 4. Change over time for in-vehicle rail congestion during peak morning hours in Tokyo: average of 31 sections between 1975 and 2010

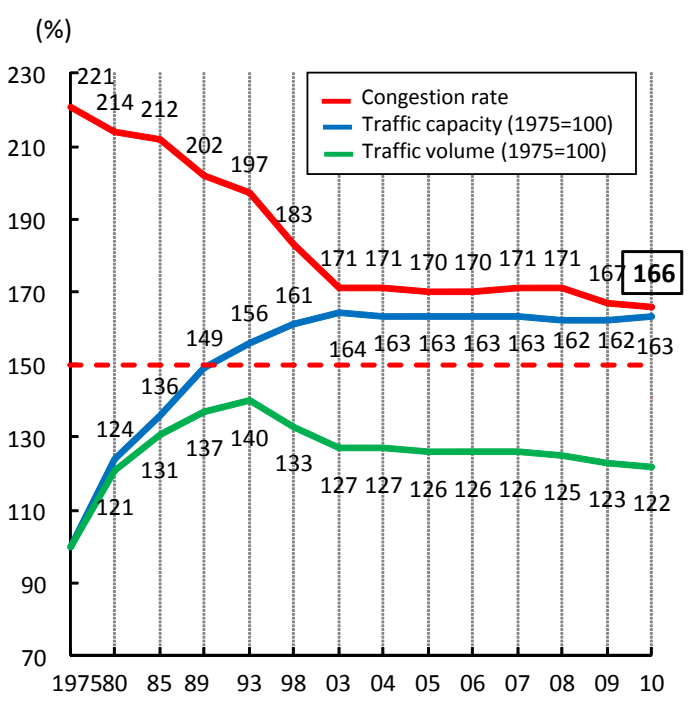

Source: MLIT (2012)

The younger generation's preference for residences in the city has increased the housing demand in the center of Tokyo, which resulted in a decrease in the demand for commuting lines from suburban areas to the CBD. On the other hand, the traffic capacity has not grown much since 2003 , which means that rail operators have stopped investing in increased capacity. This probably reflects the prolonged economic recession in Japan from the late 1990 s to 2010 . Although the average in-vehicle congestion rate slightly declined from 2009 to 2010, it remains at 166\%, which is higher than the government's target of $150 \%$.

Figure 5. Rail sections where the in-vehicle congestion rates have significantly changed between 1998 and 2010

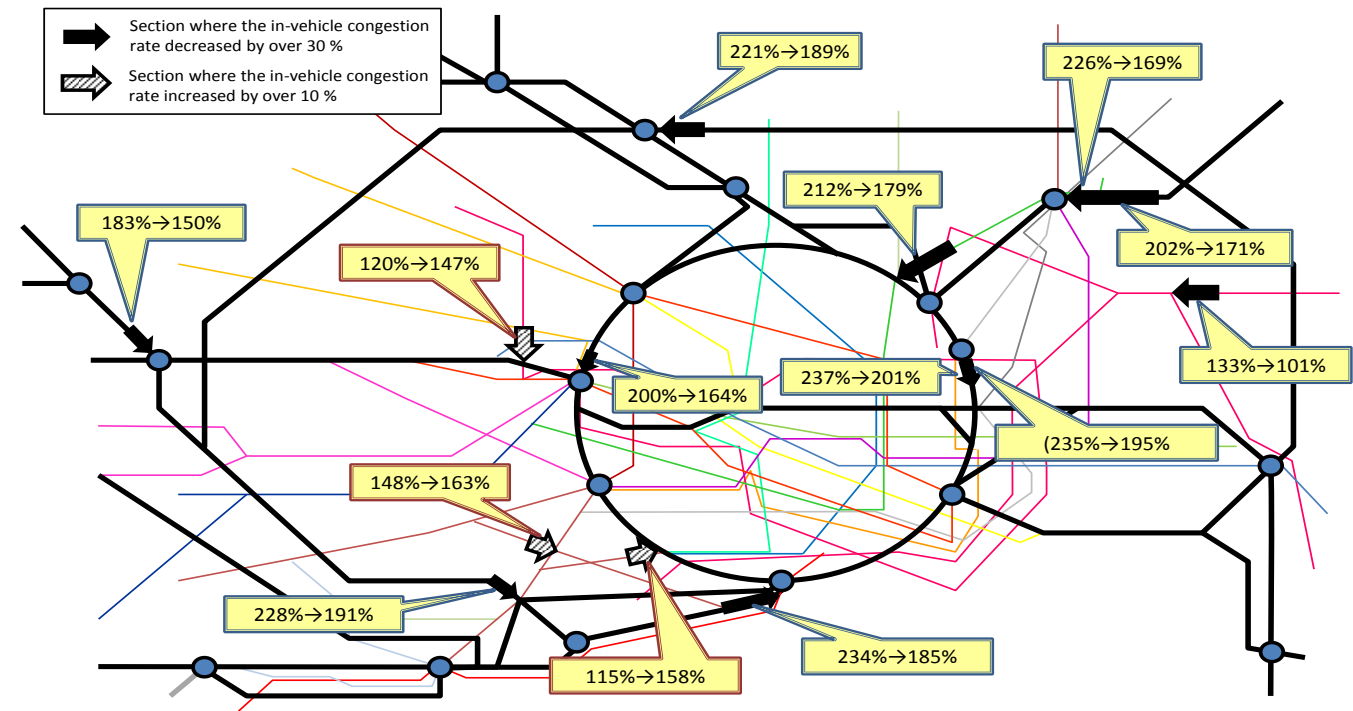

Source: MLIT 
Figure 5 shows the recent changes in the observed in-vehicle congestion during peak morning hours at the sections where the in-vehicle congestion rate has significantly changed between 1998 and 2010. This shows that many sections benefitted from the reduction of in-vehicle congestion; however, three sections in the south-western part of $T$ (2012) Tokyo faced an increase of in-vehicle congestion over the past 10 years. Major reasons for the reduction in the in-vehicle congestion include an increase in service frequency and the introduction of a wider car body.

Figure 6. Length of rail sections by in-vehicle congestion rate among the 42 major rail sections in the Tokyo Metropolitan Area

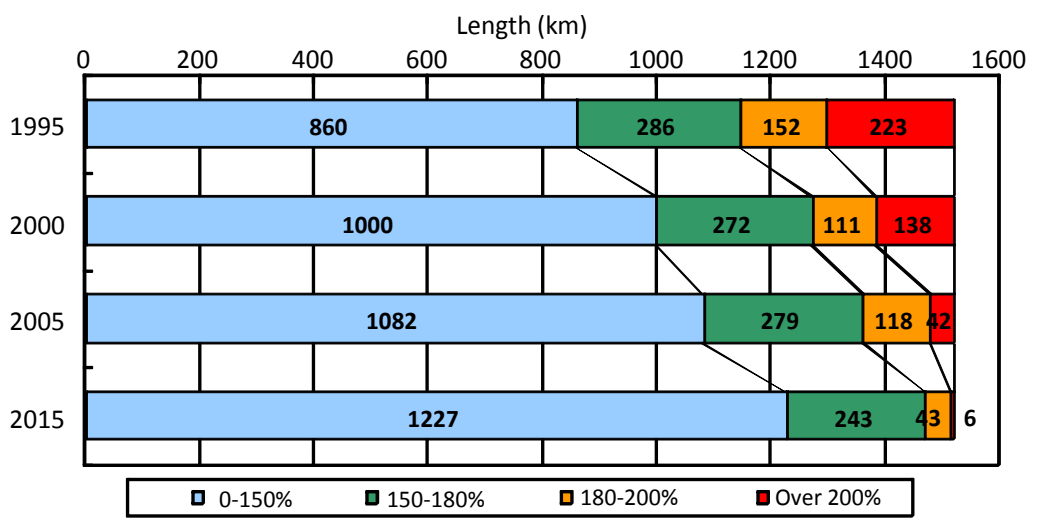

Source: MLIT (2012)

Figure 6 shows the change over time, from 1995 to 2015, for the length of rail sections by in-vehicle congestion rate among 42 major rail sections in the Tokyo Metropolitan Area. Note that the 2015 data are estimates based on the travel demand forecasted in the latest master plan, under the assumption that the construction of all A1 and A2 lines has been completed. This shows that the length of rail sections for which the in-vehicle congestion rate is greater than $200 \%$ was drastically reduced, while rail sections with an in-vehicle congestion rate of less than $150 \%$ have gradually increased over the past 10 years.

In summary, from 2000 to 2010, in-vehicle crowding was significantly reduced, mainly through efforts of rail operators to increase traffic capacity and the recent decrease in traffic demand. However, in-vehicle crowding is still very high in major rail sections, and the government target has not yet been satisfied. The prolonged economic recession and the change in land-use patterns have decreased rail operators' motivations for new investments, which has made it difficult to expect the market-oriented reduction of invehicle congestion to happen immediately.

\section{Saving travel time}

The map presented in Figure 7 illustrates the rail-use access travel time from different districts in the Tokyo Metropolitan Area to the CBD in 2010. It assumes that Otemachi station is the representative point of the CBD. The areas along major suburban rail lines that are located more than $30 \mathrm{~km}$ from the CBD can access the CBD within 90 minutes by rail, whereas most of the areas within a $20 \mathrm{~km}$ radius of the CBD can access the CBD within 60 minutes by rail. This means, first, that the rail lines connecting the CBD to suburban districts contribute to the high accessibility of the CBD commute for residents in the suburban areas. Second, it also shows that accessibility from the sub-centers to 
the CBD is also high. Note that major business sub-centers are located on the major suburban rail lines, about 30 to $40 \mathrm{~km}$ from the CBD. Third, it shows that the northeastern areas enjoy better access to the CBD via high-speed rail service thanks to the completion of the Tsukuba Express Line in 2005.

The map presented in Figure 8 illustrates changes in rail-use access travel time from different districts in the Tokyo Metropolitan Area to the CBD from 2000 to 2010. This shows that accessibility from the north-eastern areas has improved over the past 10 years. This improvement is mainly seen along the three newly introduced lines: the Tsukuba Express Line, Saitama Rail Line, and Narita Sky Access Line.

Table 1 shows the changes in the populations covered by the areas where, between 2000 and 2010, rail-use access travel time to the CBD is within 60 minutes, by type of population. The residents who reside in the area where rail-use access travel time to the CBD is within 60 minutes account for $27.2 \%$ in 2000 and $28.2 \%$ in 2010 . More individuals can access the CBD within 60 minutes in the Tokyo Metropolitan Area; this may also mean many commuters have saved time traveling to the CBD. The population of workers who work in the area where rail-use access travel time to the CBD is within 60 minutes accounted for $46.1 \%$ in 2000 and $46.9 \%$ in 2010 . More workers can access the CBD within 60 minutes in the Tokyo Metropolitan Area; this may mean that workers can improve their productivity by utilizing the time saved when traveling to the CBD.

Figure 7. Rail-use access travel time to Central Business District (Otemachi) in 2010

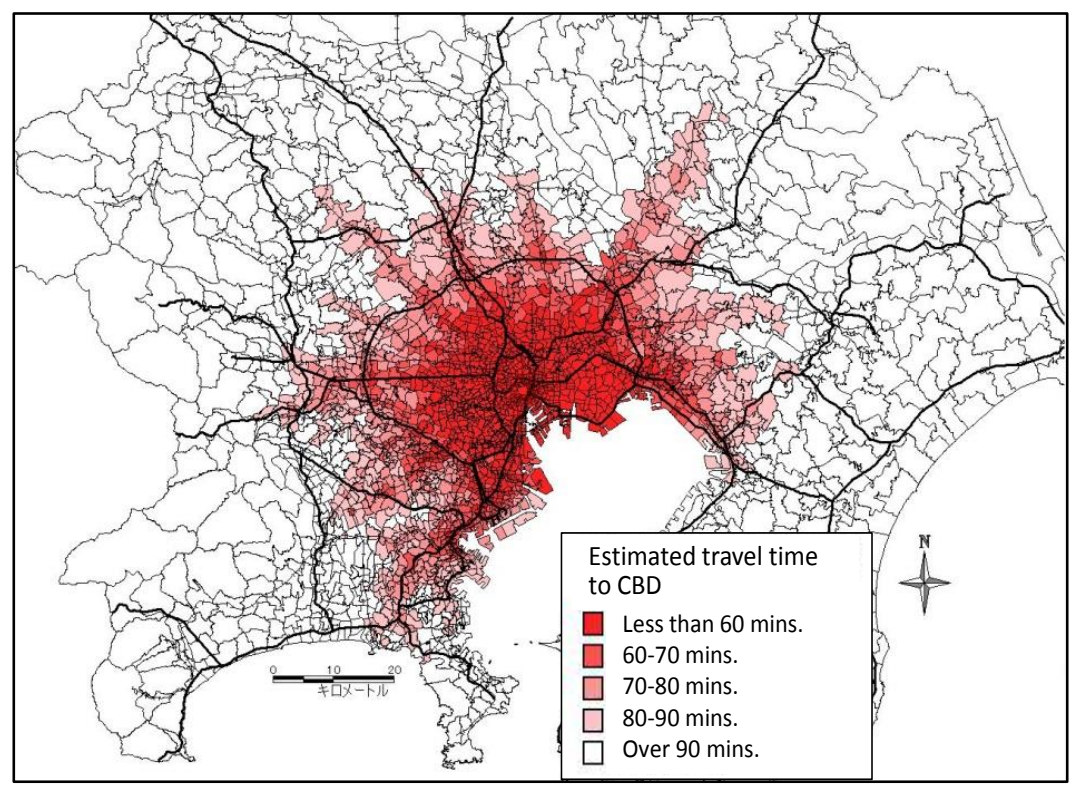

Source: MLIT (2012) 
Figure 8. Change in access time to CBD from 2000 to 2010

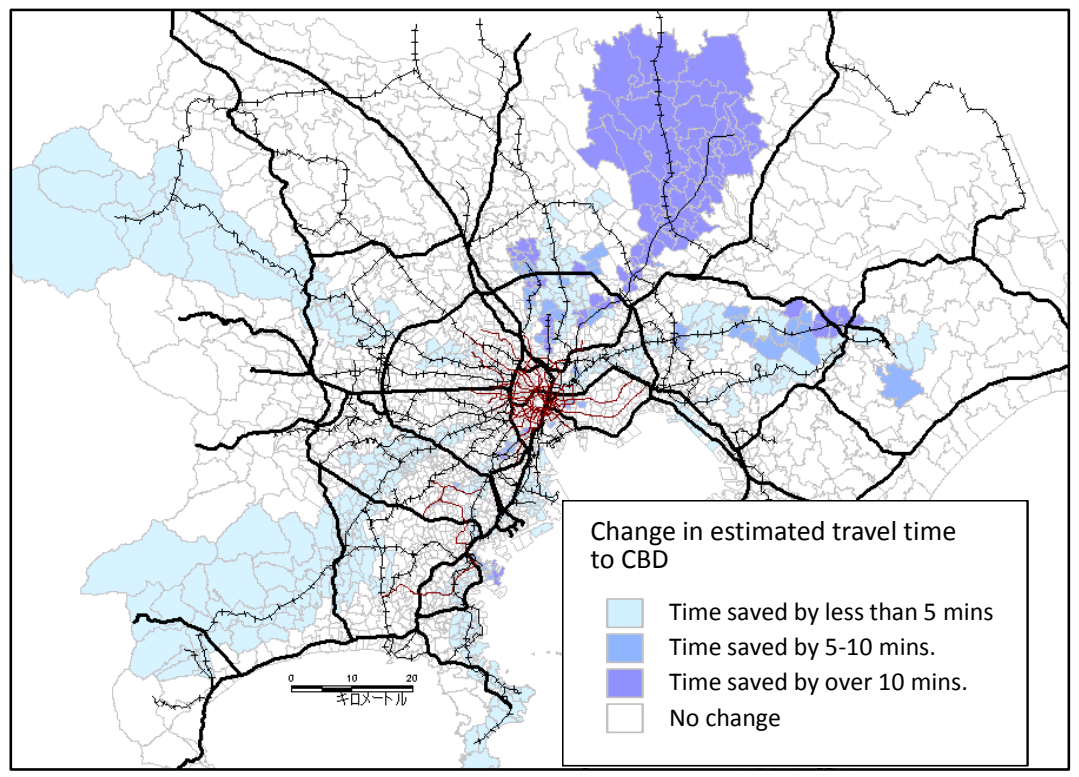

Source: MLIT (2012)

Table 1. Changes in the population within a 60-minute rail commute to the CBD from 2000 to 2010

\begin{tabular}{lrrrrr}
\hline \multicolumn{4}{c}{2000} & \multicolumn{4}{c}{2010} \\
\hline & Population (Thousand) & $\%$ & Population (Thousand) & $\%$ & \\
\hline Residents & 9,372 & 27.2 & 9,739 & 28.2 \\
Workers & 7,977 & 46.1 & 8,131 & 46.9 \\
\hline
\end{tabular}

Figures 9 and 10 show the changes in the average speed of rail service by JR rail line and by suburban rail line, respectively, from 2000 to 2010. They show that rail services in some lines, such as the JR Keiyo Line and Keisei Honsen Line, have increased the average speed. Note that both the JR Keiyo Line and Keisei Honsen Line connect the eastern part of the Tokyo Metropolitan Area with the CBD.

In summary, the recent development of urban rail has contributed to improving the CBD's accessibility for commuters traveling from the suburban areas, as well as for businesspersons traveling from their workplaces to the CBD. This improvement has been achieved through the development of new rail lines and increases in the speed of rail service made by rail operators. 
Figure 9: Changes in the average speed of rail service by JR rail line from 2000 to 2010

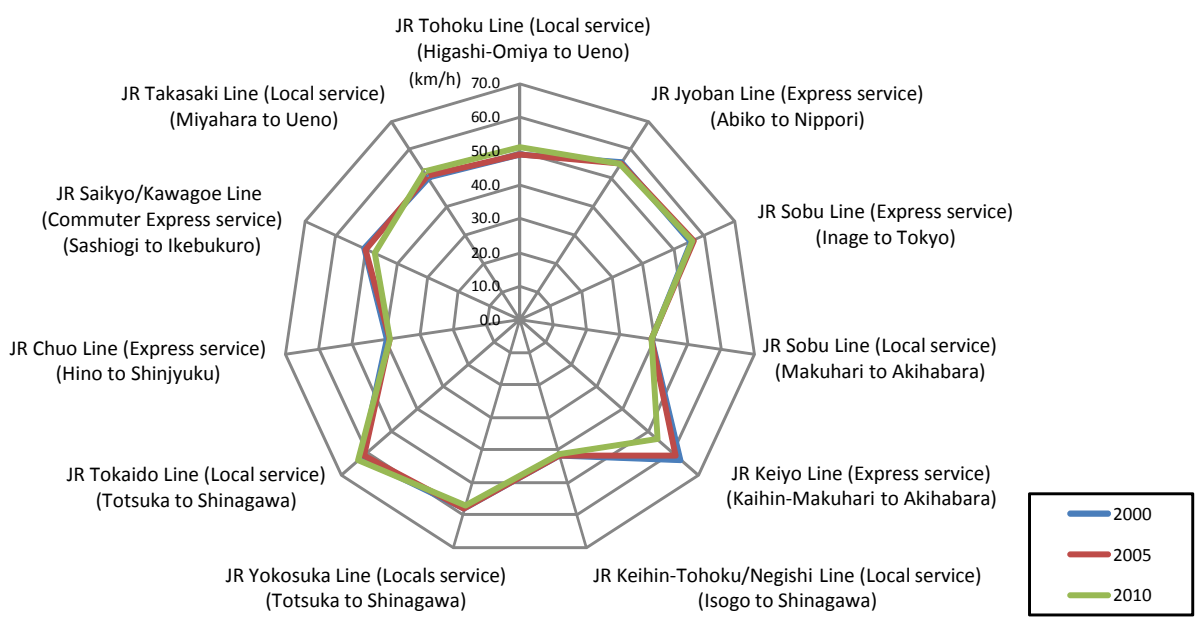

Source: MLIT (2012)

Figure 10 . Changes in the average speed of rail service by suburban rail line from 2000 to 2010

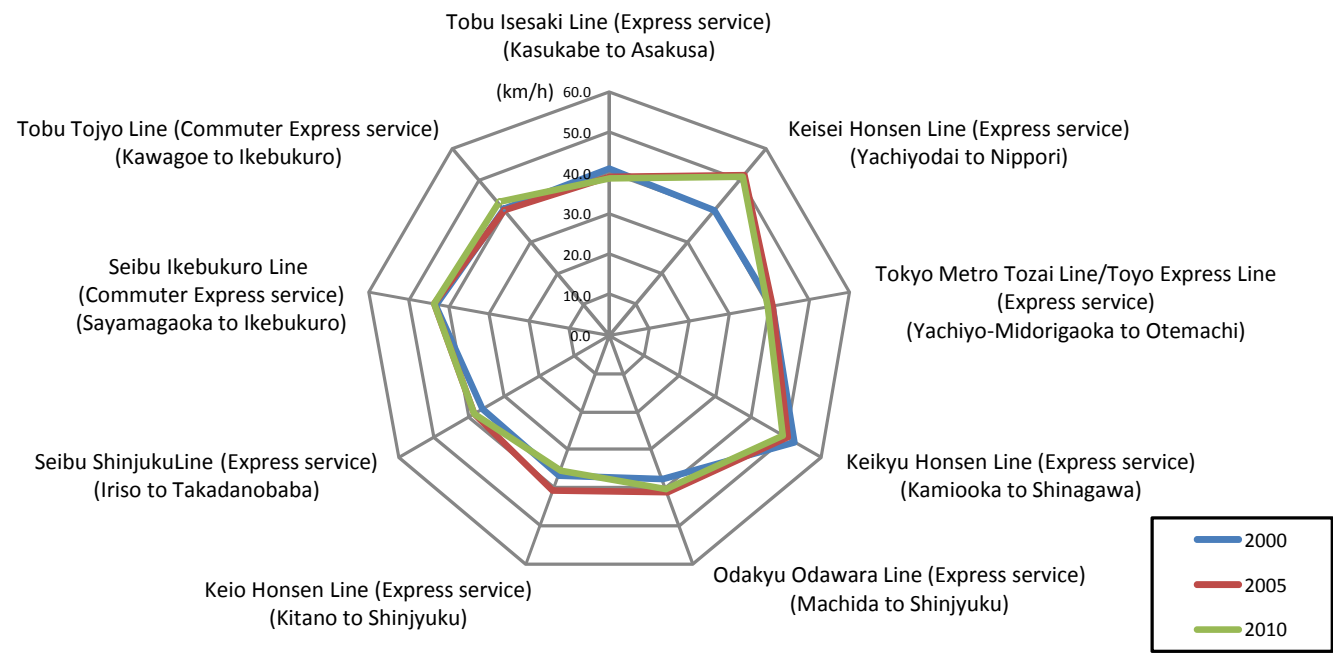

Source: MLIT (2012)

\section{Contribution to urban redevelopment}

Since the early 2000s, redevelopment in the central district of Tokyo has been boosted, particularly after the Act on Special Measures Concerning Urban Regeneration was introduced in 2002, with which the Building Standards Law was revised by relaxing the maximum floor area ratio (Deguchi et al., 2014). This led to the sharp increase of highrise buildings for residential, office, and mixed use in the central ward areas in Tokyo.

Figure 11 shows the change over time in floor areas in the 11 central wards in Tokyo by type of use from 1999 to 2008, while Figure 12 shows the change over time in the floor areas of super high-rise buildings in the 11 central wards in Tokyo by type of use from 1999 to 2008. A "super high-rise building" is defined as a building that is taller than 60 meters. Approximately $22.49 \mathrm{~km}^{2}$ of floor area was added between 1999 and 2008 in the 
11 wards, in which the floor areas of super high-rise buildings accounted for approximately $70 \%$. The rapid construction of these super high-rise buildings began in 2002, particularly in Minato and Chiyoda Wards.

This resulted in the rapid increase of traffic demands in the central district of Tokyo, including rail demand. Figure 13 shows nine major areas in central Tokyo where largescale redevelopment projects were made near the rail stations. It also shows changes in rail demand from 2000 to 2007 at each rail station. This indicates that many rail stations in the redeveloped areas have seen a significant increase in demand: for example, the number of passengers using Roppongi station increased by approximately $300 \%$.

Although serious traffic congestion in rail service could occur due to the sharp increase in rail demand at those stations, no critical problem has yet been reported. This is because potential congestion has been successfully mitigated by the introduction of new rail networks in central Tokyo, including the Toei Oedo Line, Rinkai Line, and Tsukuba Express Line, as well as by the extension of the existing Hanzo-mon Line.

Figure 11: Change over time of floor areas in the central 11 wards in Tokyo by type of use

$\mathrm{X} 100,000 \mathrm{~m}^{2}$

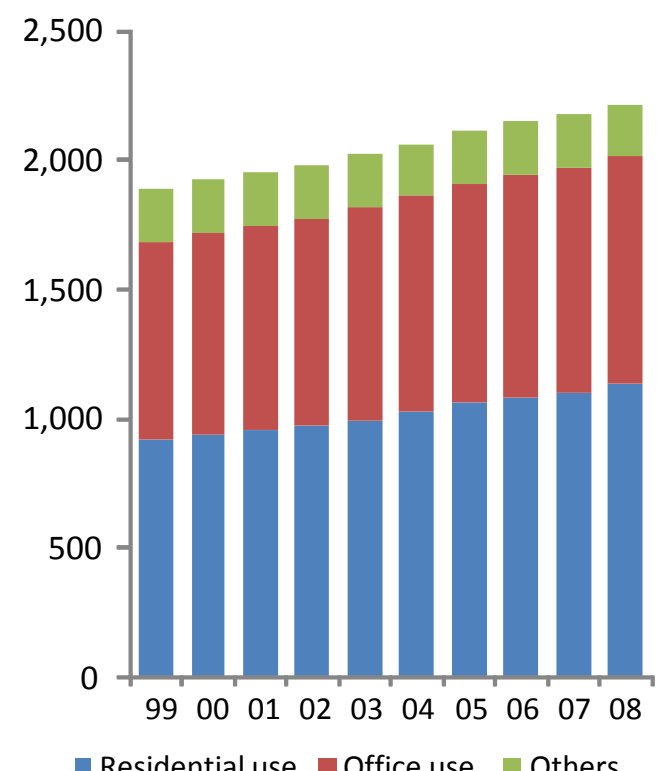

Source: MLIT (2012) 
Figure 12. Change over time of the floor areas of super high-rise buildings in the central 11 Wards in Tokyo by type of use

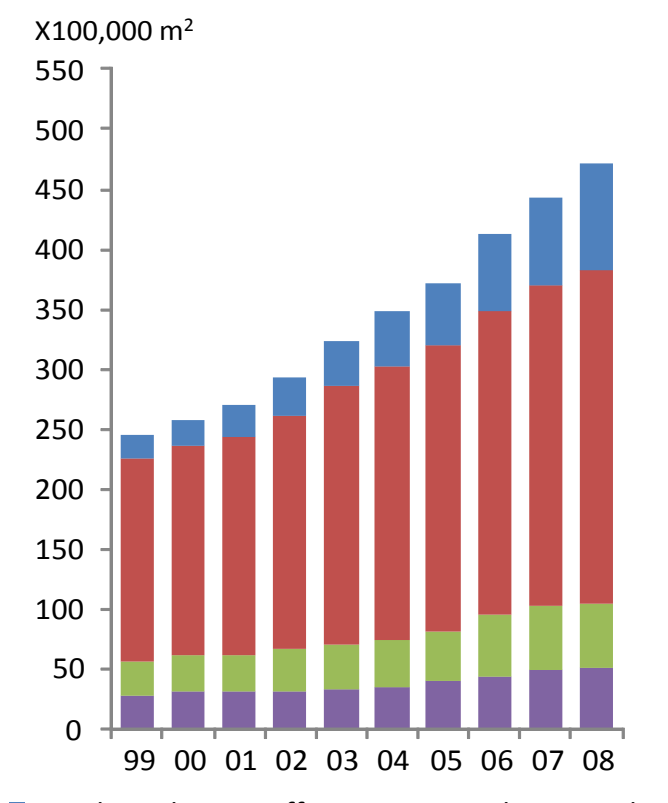

Source: MLIT (2012)

Figure 13. Changes in rail demand at major stations at which large-scale redevelopment was implemented in Tokyo

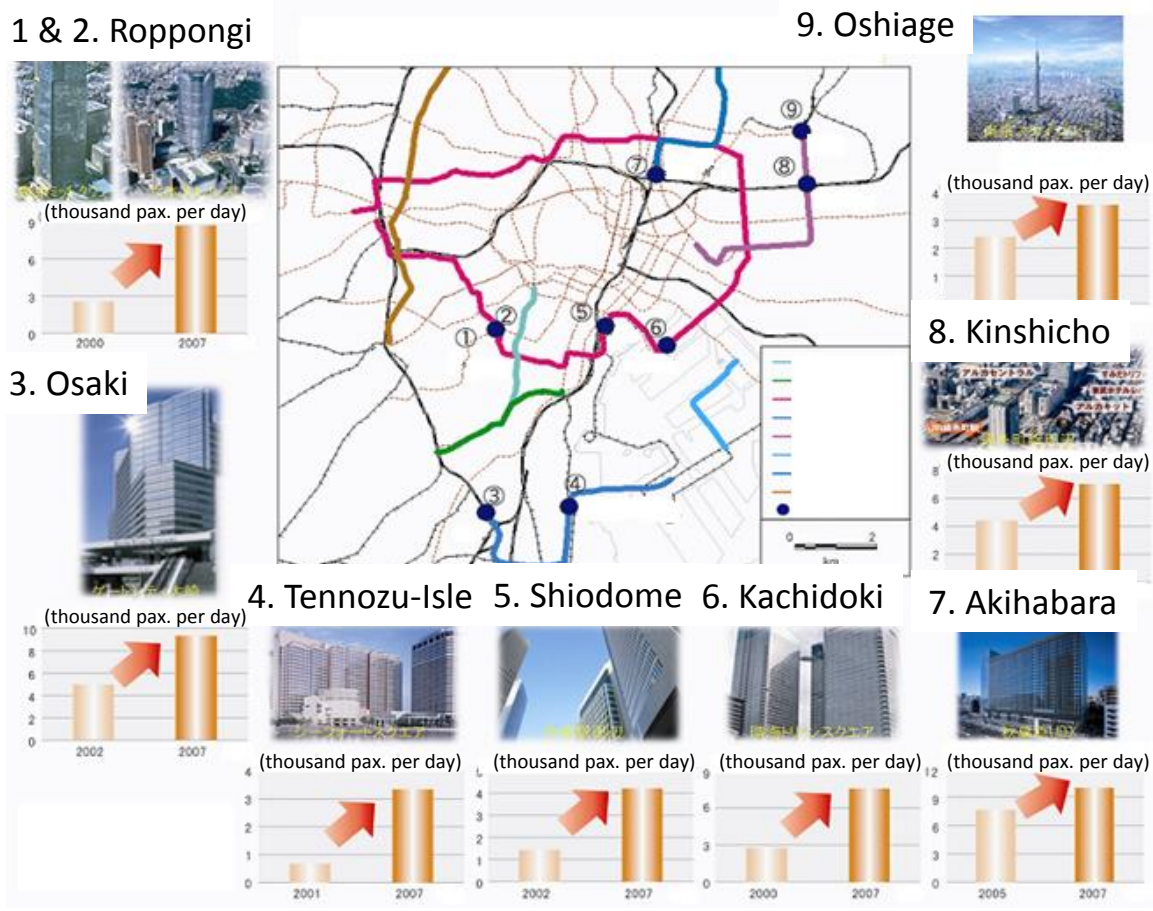

Source: MLIT (2012) 
In summary, the recent development of urban rail has contributed to mitigating rail traffic congestion in the central district of Tokyo, where large-scale redevelopment has taken place.

\section{Improving the accessibility of airports}

There are two major airports in the Tokyo Metropolitan Area: Tokyo International Airport, also known as Haneda Airport, and the Narita International Airport, also known as Narita Airport. Haneda Airport is located about $15 \mathrm{~km}$ south of Tokyo Station, whereas Narita Airport is located about $60 \mathrm{~km}$ east of Tokyo Station. Before 2010, almost all domestic flights to and from Tokyo went through Haneda Airport, whereas the majority of international flights to and from Tokyo went through Narita Airport. In 2010, a new international terminal was opened at Haneda Airport, following the completion of the fourth runway; this led to a dramatic increase in international flights to and from Haneda Airport. The air-travel demands of both domestic and international flights are expected to increase in the future due to an expected growth in overseas tourists and business travelers, mainly from East Asian and Southeast Asian countries (Civil Aviation Working Group, 2013). The national government has also promoted the tourism industry by implementing the "The Tourism National Promotion Basic Plan" (Japan Tourism Agency, 2013).

The map presented in Figure 14 illustrates changes in access time from different districts in the Tokyo Metropolitan Area to Haneda Airport from 2000 to 2010. These changes indicate that the three eastern areas have benefited travelers by reducing the time needed to access the Haneda Airport. The reduction in travel time was due to the introduction of new rail lines, such as the north-eastern-bound Tsukuba Express Line, the eastern-bound Narita Sky Access Line, and the southeaster-bound Rinkai Line.

Figure 14. Changes in access time to Haneda Airport from 2000 to 2010

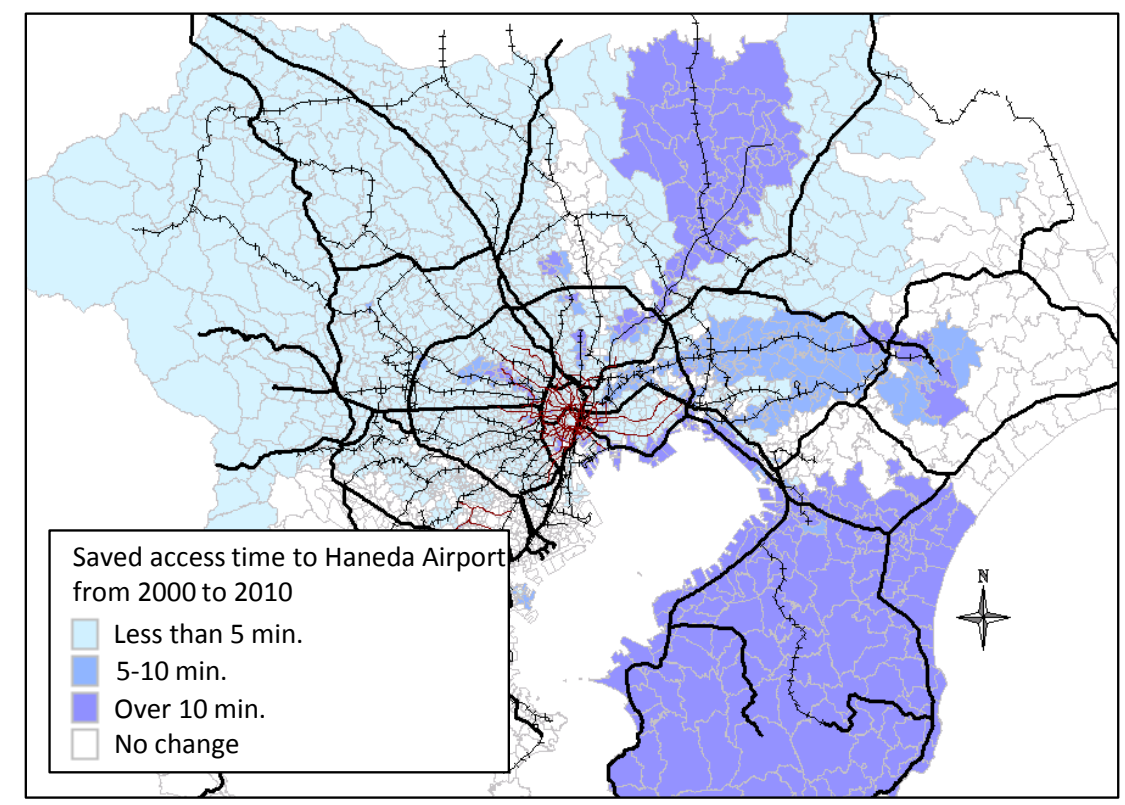

Source: MLIT (2012) 
The map in Figure 15 illustrates the changes in access time from different districts in the Tokyo Metropolitan Area to Narita Airport from 2009 to 2010. Note that the new access rail line, the Narita Sky Access Line, was introduced in 2010. This shows that many of the northern and western parts of the Tokyo Metropolitan Area saved access time to Narita Airport, whereas the eastern part of the metropolitan area did not benefit from any reduction in travel time. This is because the Narita Sky Access Line connects Narita Airport with the Tokyo CBD, whereas only a few feeder lines connect to the Narita Sky Access Line, particularly between Narita Airport and the terminal station.

Figure 16 shows the international comparison of accessibility to the main international airport for major cities throughout the world. This includes the change in access time before and after the start of operation in the Narita Sky Access Line. This comparison indicates that the Narita Airport is located much further away than other airports; the Tokyo CBD is located about $60 \mathrm{~km}$ from the Narita Airport, whereas the London and Paris $\mathrm{CBDs}$ are located about $20 \mathrm{~km}$ from their main international airports. Although access time to Narita Airport was about 50 minutes before the start of operation, the Narita Sky Access Line has reduced access time to about 35 minutes, which is close to the access time in London and Paris. This means that the Narita Sky Access Line provides highspeed rail access service.

Figure 15. Changes in access time to Narita Airport from 2009 to 2010

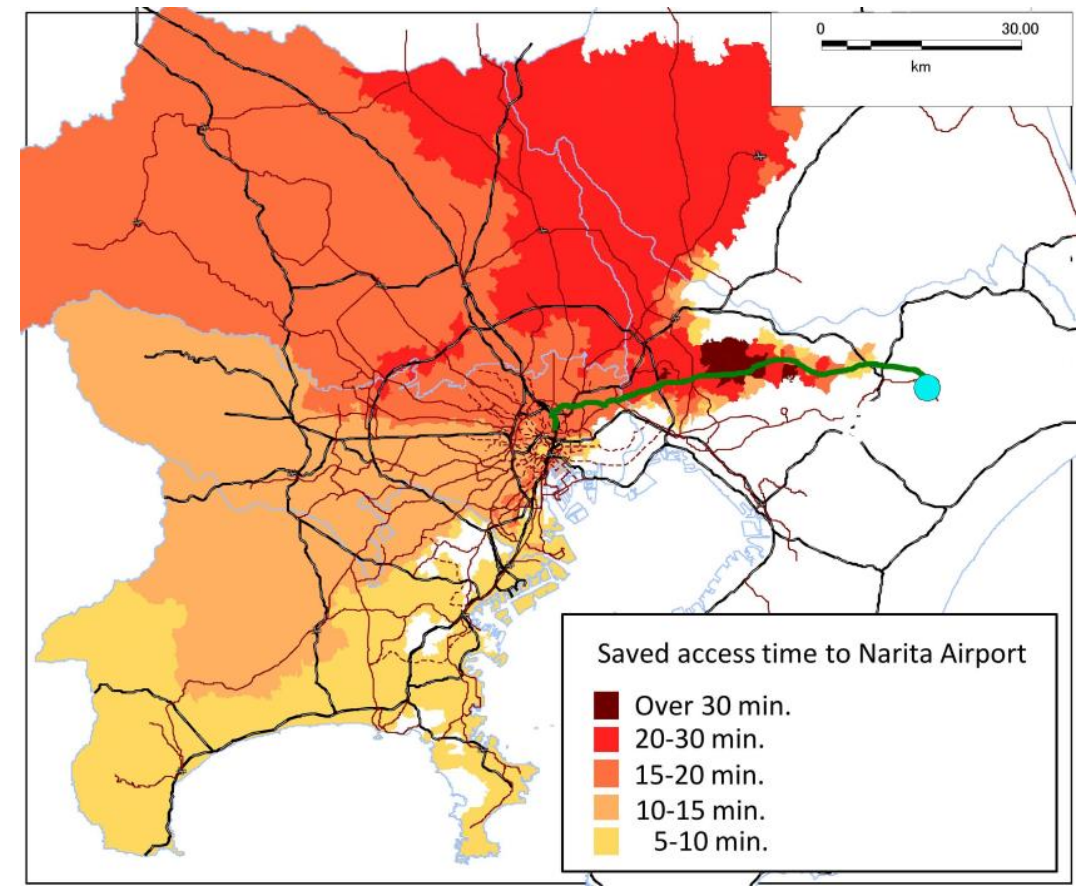

Source: MLIT (2012)

In summary, the introduction of a new, high-speed access rail-line to Narita Airport has dramatically improved the accessibility of international airline services in Tokyo, while the recent development of an urban rail network has also contributed to the Haneda Airport's accessibility for international and domestic airline services. 


\section{Figure 16. International comparisons of accessibility to the main international airport for major cities throughout the world}

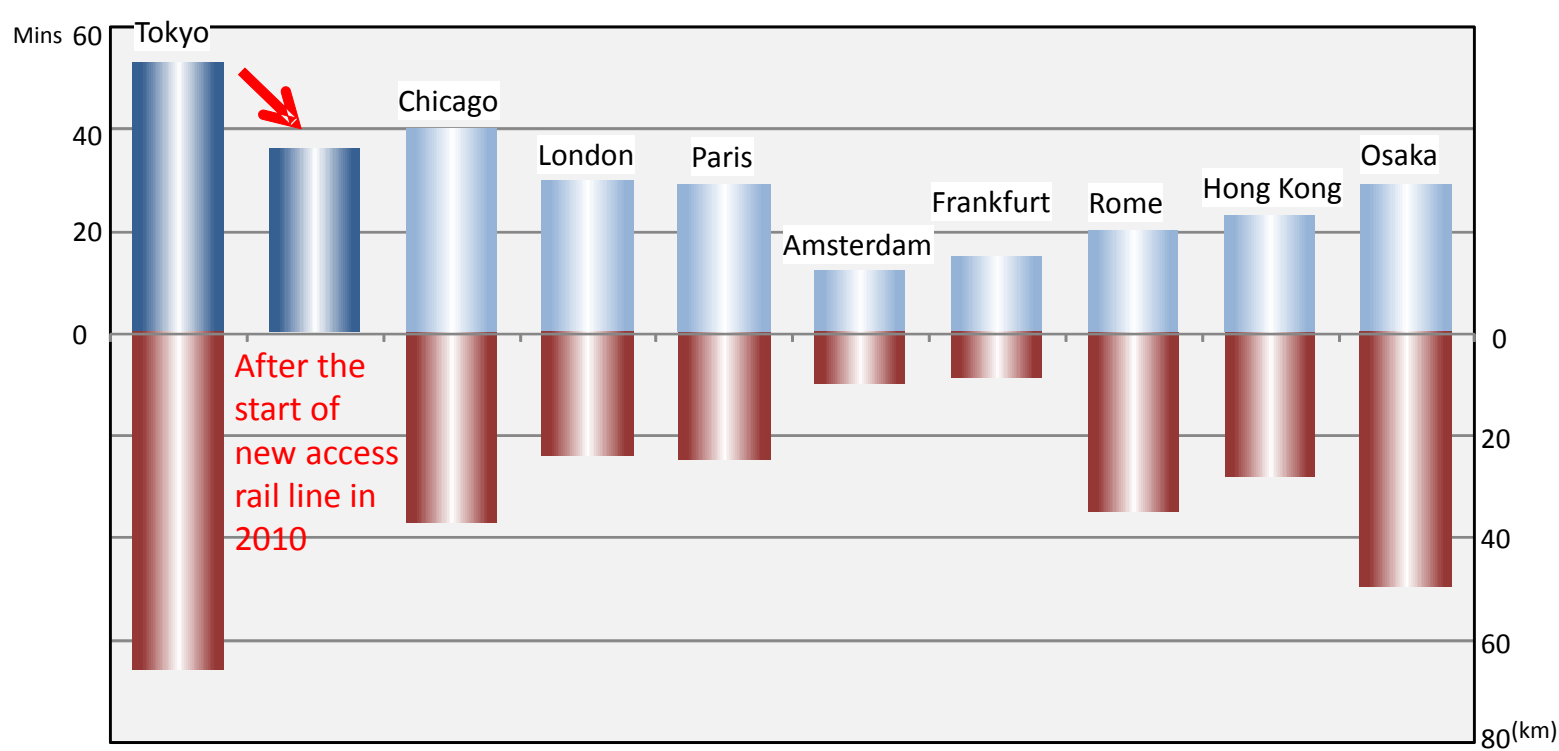

Source: MLIT (2012)

\section{The development of a seamless transport network by introducing barrier-free facilities}

Figure 17 shows the change over time for the share of stations that have over 5,000 passengers/day and have introduced a non-step route in the Tokyo Metropolitan Area. A "non-step route" refers to a path from the entrance of the station to the train platform along which an individual can move without using steps. Elevators, slopes, and escalators all support non-step routes. This shows the share of non-step-route stations has gradually increased. This reflects the government policy that introduced the Barrier-Free Act in 2000, which makes the installation of elevators and escalators in large-scale rail stations mandatory. According to the government's review, as of $2010,77 \%$ of rail stations that have more than 5,000 daily passengers had installed barrier-free facilities (MLIT, 2011). As further growth in the number of elderly rail users is expected in the coming decade, in 2011 the national government revised the Act to add a new policy target: that $100 \%$ of rail stations that have more than 3,000 daily passengers install the barrier-free facilities.

Additionally, by 2010, automatic platform screen doors had been installed in over 250 stations in the Tokyo Metropolitan Area (MLIT, 2012). These doors allow passengers to safely wait for trains in secured spaces. The smart card system was also introduced to the entire urban transportation network, including both rail and bus services, in the Tokyo Metropolitan Area. Although two different smart cards were introduced by JR East and other urban rail operators-SUICA (JR East, 2006) and PASMO (PASMO, 2013) -they are mutually compatible and allow passengers to easily change from the rail service of JR East to other rail services and vice versa. To ensure better physical connections to and from rail services, station facilities were also improved; for example, station gates were redesigned for better access between rail stations and bus services in Tsunashima Station on the Tokyu Toyoko Line. 
Figure 17. Share of stations in the Tokyo Metropolitan area that have over 5,000 passengers/day and have introduced a non-step route

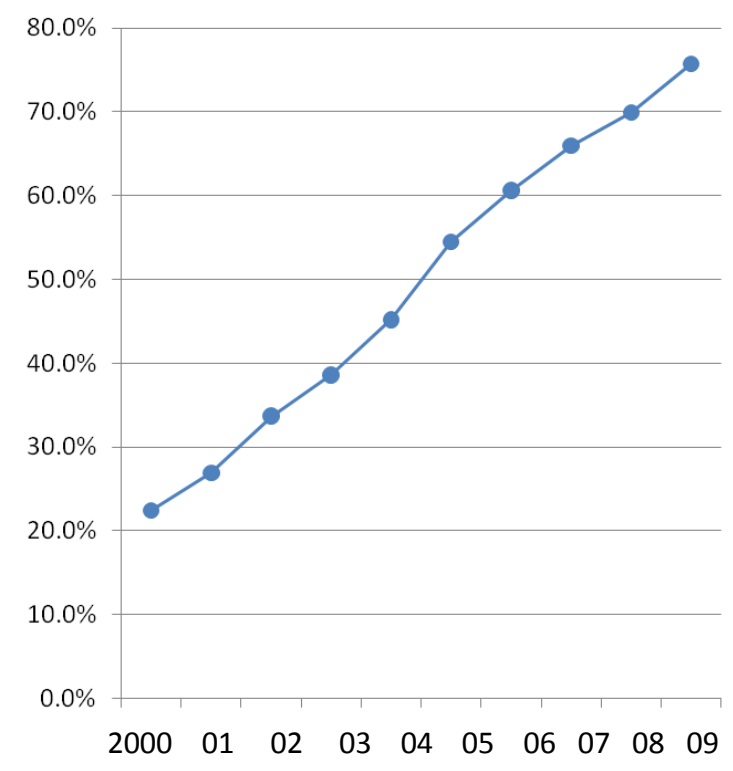

Source: MLIT (2012) 
Figure 18. Rail sections where in-vehicle congestion rates were over $\mathbf{1 8 0} \%$ as of 2010

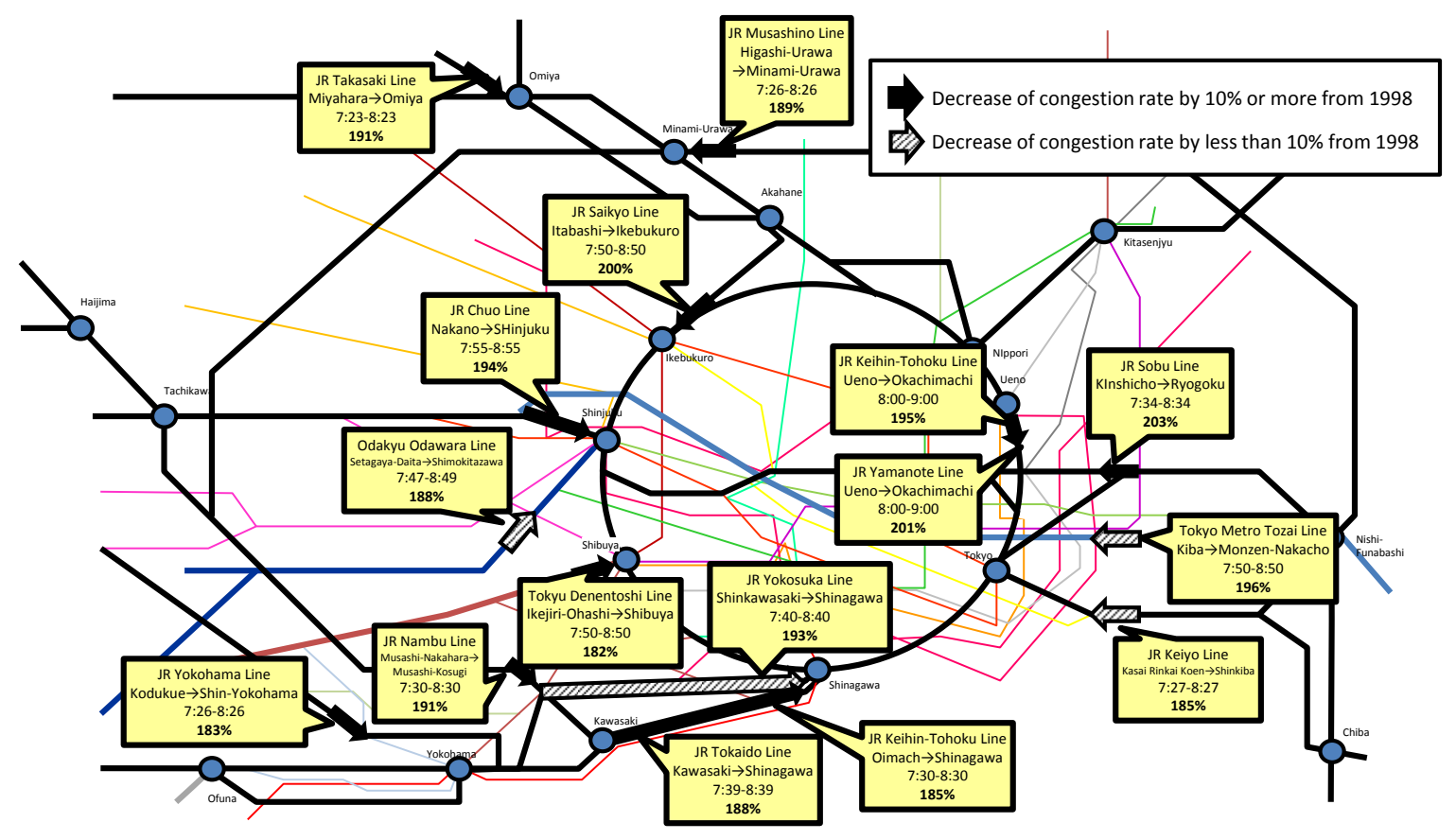

Source: MLIT (2012)

As shown in the earlier section, the recent development of the urban rail network and the improvement of urban rail service have contributed to the improvement of the Tokyo Metropolitan Area's rail service in both its quality and quantity. However, there are still many issues for improving the quality of urban rail service that need to be discussed.

First, the government's target regarding the in-vehicle congestion has not yet been reached. Figure 18 shows the rail sections where the in-vehicle congestion rates were still over $180 \%$ during peak morning hours as of 2010 , with the recent changes in the invehicle congestion rate from 1998 to 2010. Despite recent efforts to reduce in-vehicle congestion, there are still many sections facing serious congestion. This congestion mostly results from traffic flows from the suburban area to the central area. The sections connecting with terminal stations on the inner ring rail line (Yamanote Line), in particular, suffer from serious in-vehicle congestion.

One of the barriers for tackling the problem of in-vehicle congestion is the rail companies' low incentive to increase rail service capacity. First, many experts and commentators have highlighted the expected decline of the urban population in the Tokyo Metropolitan Area in the next 20 years (for example, National Institute of Population and Social 
Security Research, 2013); this reduces the rail companies' motivation to make further investments. Although passengers in some rail sections still suffer from a high in-vehicle congestion rate, passengers in other rail sections have already enjoyed a quite low invehicle congestion rate. As the in-vehicle congestion rate decreases, the profitability of rail operators should also decline, which may cause them to hesitate when increasing service frequency. Although it may be difficult to give investment incentives to rail operators, less costly measures that make the best use of existing facilities should be explored as a solution to the problem. Soft approaches, such as traffic demand management, should also be taken into consideration as methods for changing the departure time of passengers.

Second, Tokyo's urban rail service has recently suffered from frequent delays, particularly during peak morning hours. These delays on urban railway lines result in service delays across the metropolitan area, because many of the suburban rail services directly connect to the metro services in the Tokyo CBD. The so-called "direct-through operation" enables passengers to change rail services between a suburban rail line and a metro line without physical transfers at connecting stations. It was first proposed in the Report No. 1 of the Council for Urban Transport in 1956, and it has so far been gradually introduced into many of the rail lines in the Tokyo Metropolitan Area. As of 2013, the total length of rail network under the direct-though operation had reached about $880 \mathrm{~km}$, which accounts for over $35 \%$ of the total urban rail network in the Tokyo Metropolitan Area (MLIT, 2012).

Figure 19. Average service delay time during the observed days in 2010: the left two lines are directly connected, whereas the right two lines are independent

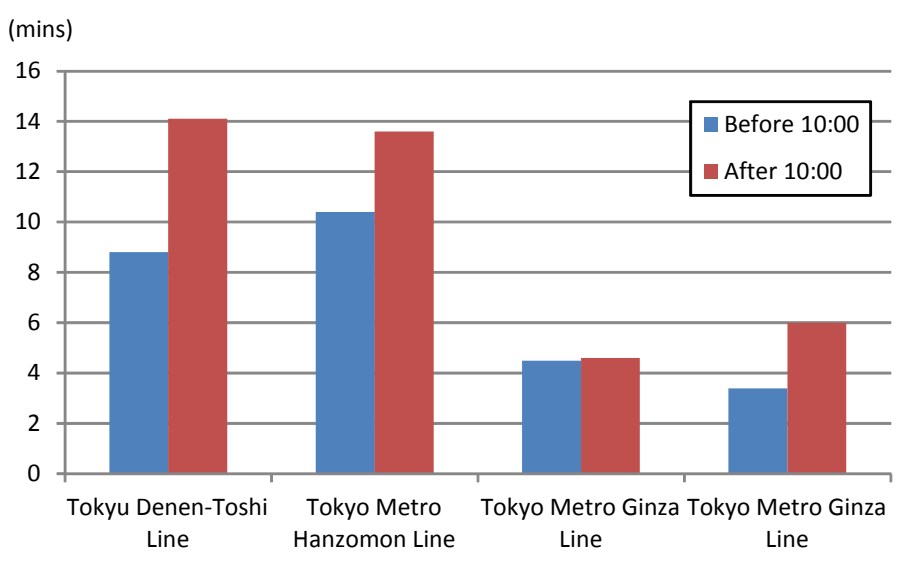

Source: MLIT (2012)

Figure 19 shows the comparison among average service delay time during the observed days in 2010 for four rail lines in the Tokyo Metropolitan Area. The Tokyu Denen-Toshi Line, one of the suburban rail lines in the western part of Tokyo, directly connects to the Tokyo Metro Hanzomon Line, one of the metro lines. The other two lines are both metro lines that run in Tokyo's central district. This shows that the rail lines with direct-though operation suffer from longer service delays than those without it. It also shows that the service delay after 10:00 a.m. is longer than the delay before 10:00 a.m. Note that the morning peak hour is from 7:00 to 8:00 a.m. for the suburban rail lines, whereas it is from 8:00 to 9:00 a.m. for the metro lines. This means that the rail lines with directthough operation suffer, even after the morning peak hours. This is because the rail service is provided over a long distance, including both the suburban line and the metro line, and the service delay occurred over too great an area to be quickly adjusted. 
Note that, for rail-service delays of up to 30 and 60 minutes, the economic losses were estimated to be approximately JPY 60 million and more than JPY 200 million, respectively (MLIT, 2009).

One of the major factors causing service delays in the urban rail network is the lack of capacity in the rail stations in the Tokyo CBD. As shown earlier, recent urban redevelopment has increased rail demand at the CBD stations; additional redevelopment is expected to put further pressure on the capacity of the rail stations (Mori Building, 2013). For example, a large-scale redevelopment project is being planned near Toranomon station in the CBD, which is expected to significantly increase rail demand. It could cause serious traffic congestion at the station platform spaces, station stairs, station gates, and station entrances. There is some concern that this congestion could result in further service delays, particularly in rail lines under the direct-through operation.

One of the difficulties facing metro rail operators is the investment cost for increasing station capacity. The metro station is, by nature, located underground in urbanized areas; this makes the construction technically difficult and increases construction costs. Thus, it may be claimed that the negative externalities of urban redevelopment should be jointly covered by rail operators and developers (Urban Renaissance Agency, 2013). There are some examples of the joint financing of rail-station development, including that of the developers near the station and rail operators, such as the renovation of the Tokyo Station (Suzuki and Murakami, 2014). A new partnership-agreement program among stakeholders, or an innovative financial scheme based on a private-public partnership, may be required.

Third, disaster mitigation measures for rail services and smart reaction/recovery processes after a natural disaster are also strongly required. The Great Tohoku Earthquake struck the northern part of the main island on March 11, 2011, and it also had a serious impact on urban rail service in the Tokyo Metropolitan Area; many rail operations were suspended for many hours, even though the rail facilities were not physically damaged. This caused serious mobility problems, particularly for workers who still needed to return home. Some rail services were stopped overnight while the road network was completely halted due to the serious traffic congestion, forcing a number of workers in the CBD to walk for many hours in order to return home, arriving late in the evening or even during the late night (Hiroi et al., 2011). Even in the days after the earthquake, some rail operators closed the station facilities or reduced the service frequency due to their fear of a second or even third attack of an after quake, causing inconvenience and traffic congestion for rail users for days. Additionally, the shutdown of nuclear power plants in Fukushima required energy-saving measures, even in urban rail operations; this created poor urban rail service for many days (Hyodo, 2011). A series of such events strongly impressed the importance of urban rail service in the Tokyo Metropolitan Area on many people. The government and rail operators started to examine disaster mitigation and adaptation plans, including reinforcing existing facilities, sharing information among stakeholders during an emergency, jointly planning terminal stations in order to avoid accidents, the availability of alternative bus service, etc. (for example, Cabinet Office, 2012; Muroi, 2012). The government also recommended that private firms prepare business-continuity plans, which include the reactions required during the risk event, the responses, the adaptation needed shortly after the risk event, and the recovery from the disaster. An integrated approach against a disaster in the context of urban rail service should be further examined. 


\section{CONCLUSIONS}

This paper reported on urban rail development in the Tokyo Metropolitan Area following the latest master plan proposed in 2000 and discussed recent policy issues that may be raised as key issues in the next master plan.

Tokyo is Japan's capital city and the most populated in the nation. It has been the center of Japan for years, and its central roles in political, business, financial, industrial, educational, and even academic functions are expected to play a leadership role in Japanese society, even during the coming age of population decline. A major infrastructure that supports urban activities in this megacity is the urban rail system.

Recently, the importance of enhancing Tokyo's international competitiveness has frequently been pointed out. For example, the Tokyo Metropolitan Government has proposed introducing Tokyo's Special Zone for Asian Headquarters, where over 500 foreign companies would be invited to five central zones in Tokyo (Tokyo Metropolitan Government, 2012). Introducing an urban rail service that accesses these zones may be highly expected, as well as a service connecting the zones to the international airports. Next, a new direct rail line connecting Narita Airport with Haneda Airport has also been proposed (Sankei Shinbun, 2013). This is also expected to enhance Tokyo's international status. Note that this may also reflect a strong demand from people in local regions, who are required to change from domestic airline service at Haneda Airport to international airline service at Narita Airport. It should be noted that this proposal may be highly influenced by the demarcation of the two airports in the Tokyo Metropolitan Area, which is one of the major issues in Japan's air transportation policy.

On the other hand, peri-urban areas, or the edges of metropolitan areas, have been facing a decrease in population due to rapid aging; this includes the northern part of Saitama Prefecture and the southern parts of Chiba, Ibaraki, and Tochigi Prefectures. The rail operators in those areas suffer from a decline in demand, and even serious deficits. The motorization spiral, in which poor rail service leads to an automobile-oriented lifestyle and urban structure, has already begun in such areas. Although local people prefer maintaining the rail service, which could represent the regional identity or symbol in the long term, they also find it difficult to increase the ridership of old rail services. Regenerating the declining economies in those areas is probably required to overcome this challenge, but a successful approach is still under investigation.

Declining rail demand along the edge of the Tokyo Metropolitan Area may be a part of the processes of a shrinking city, in which rapid aging and low birth rates lead to the decline of both the urban area and its population (Ohno et al., 2008). Similar changes in socio-demographic patterns are also expected to emerge in many other matured cities in OECD member countries in the near future (Bloom et al., 2011). Thus, Tokyo's recent challenges may be suggestive to them-aggressive transportation investment in the central district for enhancing international competitiveness along with deliberative discussions at the edge of the metropolitan area for smartly shrinking the city. 
Additionally, the Chuo Shinkansen, a new Japanese line that uses the superconducting maglev system, is planned to connect Tokyo with Chukyo, and ultimately with Kinki (JR Central, 2013). The line is expected to connect Tokyo and Nagoya in the first stage in 40 minutes, and eventually Tokyo and Osaka in 67 minutes, running at a maximum speed of $505 \mathrm{~km} / \mathrm{h}$. Its development plan was formally determined in 2011 . Operation between Tokyo and Nagoya is expected to start in 2027, while operation between Tokyo and Osaka will start in 2045. The introduction of new high-speed maglev should influence the urban rail market in the Tokyo Metropolitan Area.

Furthermore, the 2020 Summer Olympic and Paralympic Games in Tokyo have boosted massive investment of new facilities and infrastructure in Tokyo, including rail network. This is also expected to make a great opportunity where the sophisticated rail system in Tokyo appeals to international visitors; and it may lead to the increase of tourists and businesspersons to Japan.

Many new issues are emerging related to the urban rail market in the Tokyo Metropolitan Area, as shown above. The next master plan should probably cover a broader scope while simultaneously incorporating those issues. I hope the urban rail network in the Tokyo Metropolitan Area will manage to handle those problems in innovative ways.

\section{ACKNOWLEDGMENTS}

The data shown in this paper refer to documents used in the Committee on Current Problems and Future Direction of Railway Development in the Tokyo Metropolitan Area. I am grateful to Mr. Shinichiro Kato (Institute of Transport Policy Studies) and Mr. Yoshihisa Yamashita (Creative Research and Planning Co.) for their support with the data. 


\section{REFERENCES}

Bloom, D. E., Boersch-Supan, A., McGee, P. and Seike, A. (2011) Population aging: Facts, challenges, and responses, PGDA Working Paper, No. 71, Harvard Center for Population and Development Studies.

Cabinet Office, The Government of Japan (2012) Final Report on Committee on the Countermeasure Taken against the Travelers Who Have Difficulties in Returning Home under Tokyo Local Earthquake, September 2012. (in Japanese)

Central Japan Railway Co. (JR Central) (2013) Central Japan Railway Company Annual Report 2013, available at http://english.jr-central.co.jp/company/ir/annualreport/_pdf/ annualreport2013.pdf, last accessed on March 13, 2014.

Civil Aviation Working Group, The Council for Transport Policy (2013) On the future direction of airports in the Tokyo Metropolitan Area, Document 2-1, Civil Aviation Bureau, Ministry of Land, Infrastructure, Transport and Tourism, Japan, September 2013. (in Japanese)

Deguchi, A., Song, J., Yoshida, M. and Okada, M. (2014) Age of clustering super highrise buildings: Tokyo downtown at outset of the 21st century overviewed through analysis on tower construction trend, City Planning Review, Vol. 63, No. 1, pp. 10-15. (in Japanese)

East Japan Railway Co. (JR East) (2006) Suica User's Guide, available at http://www.yestokio.es/pictures/moversextokio/Suicauserguide.pdf, last accessed on March 13, 2014.

Hiroi, U, Sekiya, N., Nakajima R., Waragai, S. and Hanahara, H. (2011) Questionnaire survey concerning stranded commuters in metropolitan area in the East Japan Great Earthquake, Journal of Social Safety Science, Vol. 15, pp. 1-11. (in Japanese)

Hyodo, T. (2011) Impacts of saving energy on rail transportation in the Tokyo Metropolitan Area, JSCE Magazine "Civil Engineering," Vol. 96, No. 6, p. 23. (in Japanese)

Japan Tourism Agency (2013) The Tourism Nation Promotion Basic Plan, January 2013, available at http://www.mlit.go.jp/kankocho/en/kankorikkoku/kihonkeikaku.html, last accessed on March 13, 2014.

Kato, H. (2014) Valuation of urban rail service: Experiences from Tokyo, Japan, International Transport Forum's Discussion Paper Series, No. 2014-1, OECD, pp. 1-29.

Ministry of Land, Infrastructure, Transport, and Tourism (MLIT) (2009) Research Report on Impacts of Troubles in Rail Service (Abstract). (in Japanese) 
Ministry of Land, Infrastructure, Transport, and Tourism (MLIT) (2011) Partial revision of basic strategy on the promotion of smoothing travels, available at http://www.mlit.go.jp/common/000141702.pdf, last accessed on January 11, 2014. (in Japanese)

Ministry of Land, Infrastructure, Transport, and Tourism, Japan (MLIT) (2012) Final Report of Research Committee on Current Problems and Future Direction of Railway Development in the Tokyo Metropolitan Area. (in Japanese)

Mori Building Co. (2013) Survey of the large-scale office building market in Tokyo's 23 wards, October 2013, available at http://www.mori.co.jp/en/img/article/131002.pdf, last accessed on March 13, 2014.

Morichi, S., Iwakura, S., Morishige, S., Itoh, M. and Hayasaki, S. (2001) Tokyo metropolitan rail network long-range plan for the 21st century. Presented at the Annual Meeting of Transportation Research Board, Washington, DC, January 2001.

Morichi, S. (2000) History and Future of Urban Rail System in the Tokyo Metropolitan Area, Institution of Transport Policy Studies. (in Japanese)

Muroi, K. (2012) Study of buses substituting for trains when people experience difficulties getting home, Transportation and Economy, Vo. 72, No. 9, pp. 41-50. (in Japanese)

National Institute of Population and Social Security Research (2013) Household projections for Japan 2010-2035: Outline of results and methods, available at http://www.ipss.go.jp/pp-ajsetai/e/hhprj2013/hhprj130304_DL.pdf, last accessed on March 13, 2014.

Ohno, H. with Urban Associates (2008) Shrinking Nippon: Future Strategy of Shrinking Cities, Kajima Institute of Publishing Co. Ltd., Tokyo. (in Japanese)

PASMO, Co. (2013) PASMO guide, available at http://www.pasmo.co.jp/en/pdf/ pasmo_resident_E.pdf, last accessed on March 13, 2014.

Suzuki, H. and J. Murakami (2014) Financing Transit with Land Development. (forthcoming)

The Sankei Shimbun (2013) Direct connection between Narita and Haneda for one hour: A new rail line developed jointly public and private under the national growth strategy, planned to start operation by 2030s, May 31, 2013.

Tokyo Metropolitan Government (2012) Your base for new innovation: Introducing Tokyo's Special Zone for Asian Headquarters, available at http://www.chijihon.metro.tokyo.jp/ahq_project/english/resources/pdf/ahp_en_0625.pdf, last accessed on March 13, 2014.

Urban Renaissance Agency (2013) Renewal of Urban Development and Railway: Towards Enhancing International Competitiveness of Tokyo. (in Japanese) 
